\title{
A newly diagnosed HIV patient with paraplegia: what could be a possible cause?
}

\author{
Yhan Batista ${ }^{a^{*}}$, Usman Hadi ${ }^{\mathrm{b}}$ \\ a yhanbatista.md@gmail.com \\ ${ }^{a}$ Department of Internal Medicine, Airlangga University-Dr Soetomo General Hospital, Prof. Dr. Moestopo St. No 6 - 8, Surabaya \\ 60286, Indonesia \\ ${ }^{b}$ Division of Tropical and Infectious Diseases, Department of Internal Medicine, Airlangga University-Dr Soetomo General Hospital, \\ Prof. Dr. Moestopo St. No 6 - 8, Surabaya 60286, Indonesia
}

\begin{abstract}
Background: Opportunistic infections (OIs) are clinical clues for clinicians to suspect an HIV or AIDS diagnosis and often patients contact healthcare due to OI, not because of HIV infection itself. OIs come with various clinical presentations which pose difficult challenges for clinicians to diagnose and treat.

Case description: A young male was referred due to progressive weakness of both limbs in the last two months prior to admission. Physical examination showed loss of sensation in thoracal segment level VII-VIII. Laboratory tests showed positive HIV tests, low CD4 and detectable HIV RNA load. MRI showed tuberculomatous lesion in spinal cord thoracal vertebrae level I-X and syringomyelia. Patient received cotrimoxazole, antituberculous drugs and antiretroviral drugs but he died before anti-tuberculous treatment complete.

Conclusion: Intramedullary spinal tuberculosis is very rare, and its clinical presentation is unspecified. Neuroimaging such as MRI should be a mandatory to be performed since histopathological tests sometimes are unable to undergo. Pharmacological treatment is based on clinical judgement and surgical intervention should be offered if any indications exist.
\end{abstract}

Keywords: HIV; AIDS; spinal cord; opportunistic infections; tuberculosis

\section{Introduction}

Human immunodeficiency virus was first identified by Luc Montainer in 1983, is a family of retroviruses transmitted through body fluids (Nasronudin, 2014). United Nations Program on HIV/AIDS data shows globally about 37 million people were living with HIV in 2017 with new cases finding 1.8 million (UNAIDS, 2018). Before the era of antiretroviral therapy, AIDS patients survive only 1-2 years after being diagnosed. The breakthrough of AIDS therapy decreases mortality and morbidity due to OIs (CDC, 2019).

Paraplegia is a neurological deficit due to spinal cord damage that can interfere with the work of the motoric, sensory and autonomic nervous systems. The cause of paraplegia is classified into traumatic and nontraumatic. The etiology of paraplegia includes vascular, inflammation, toxin, non-inflammatory, and metabolic lesions. (Schwenkreis et al., 2006). Infection can cause paraplegia and is classified into two types, involving medulla spinalis and infections in vertebral column causing spinal cord compression. (Abbasi \& Farkhadni, 2014). This case report will present a rare case where a newly diagnosed HIV patient with inferior paraplegia, suspected as an intramedullary spinal tuberculosis.

\section{Case Description}

A male, 29-year-old, was referred with chief complain weakness of both limbs. Lower extremity weakness was gradually felt past 2 months. The complaint was preceded by numb sensation and intermittent back pain. Three days before admission, he could not urinate, so he received urinary catheter insertion at nearest healthcare service. He complained intermittent low-grade fever past three months. He also felt he lost weight approximately 10 kilogram in past six months due to low appetite. He felt no morning erection in the last 4 weeks ago. Recently, he can only urinate through catheter and not yet defecate in past four days. There is no 

stable. General examination found no abnormality. Neurologic examination found no meningeal sign, loss of sensation in thoracal segment level VII-VIII. Motoric of both limbs are zero and Chaddock and Babinsky signs are positive. Digital rectal examination found decreased anal sphincter tone.

Laboratory investigation showed normal blood count, liver, and renal function tests, increased CRP to $115 \mathrm{mg} / \mathrm{dL}$, normal LDH level, normal CEA level, normal PSA level, normal VDRL level and positive HIV tests. CD4 count 95 cells $/ \mathrm{mm}^{3}$ and HIV viral load $1,5 \times 10^{6}$ copies $/ \mathrm{mm}^{3}$.
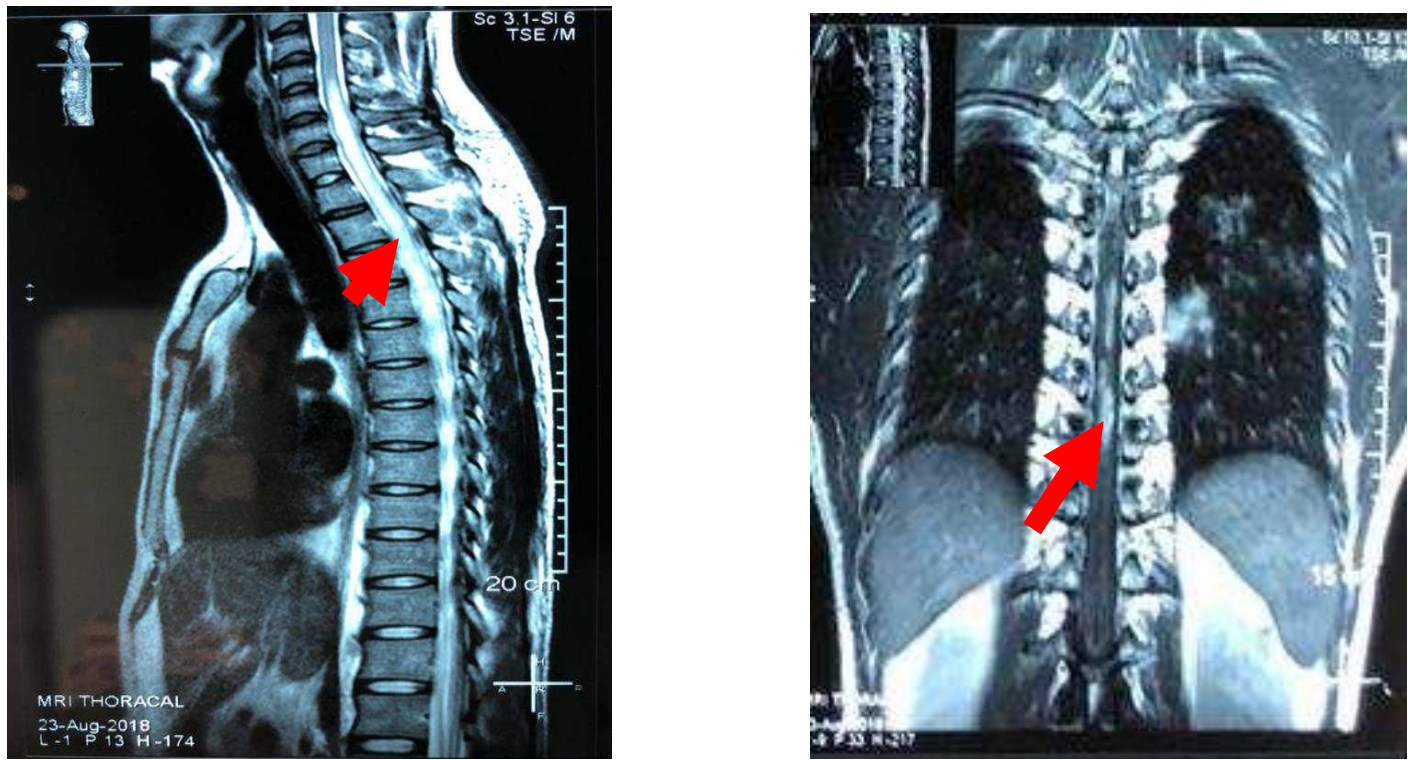

Figure 1. (Left) sagittal view of thoracal MRI; (Right) coronal view of thoracal MRI

Thoracal contrast MRI showed tuberculomatous lesion in spinal cord thoracal vertebrae level I-X that caused syringomyelia in cervical vertebrae level I to intervertebral space thoracal vertebra XI-XII, no bulging disc, no bulging neural canal and nerve root in thoracal vertebra. Patient refused surgery then he was treated with cotrimoxazole, NSAID and antituberculosis drugs. He was discharged after four days admission. Due to distance with healthcare facilities, follow up was performed by phone. He received antiretroviral drugs two months after antituberculosis drugs initiation. After taking medication after six months, he was able to move both limbs, but he died two months later due to pneumonia.

\section{Discussion}

Neurological abnormalities due to medulla spinal disorder occur in the spinal cord segment affected by the lesion and the segment below it. Spinal cord disorders cause a pattern of neurological deficits that vary depending on the neural pathways in the spinal medulla or nerve roots outside the damaged spinal cord, can be sensory, motor abnormalities or both depending on the affected area. Medulla spinalis dysfunction causes paresis, loss of tactile sensation, reflex changes, and impaired autonomic systems such as urination disorders, bowel movements, erectile dysfunction, and inability to sweat. Magnetic resonance imaging is the most accurate imaging for spinal medulla disorder because it has visualization of parenchyma, soft tissue lesions (abscesses, hematomas, tumors, intervertebral disc abnormalities) and lesions on the bones. Myelography is recommended only to patients who are unable to perform an MRI examination (Rubin, 2018). In this patient, paraplegia occurred progressively without trauma preceded and MRI suggested intramedullary spinal tuberculoma lesions. 
Table 1. Sensory and motor disorders due to spinal cord lesions based on segment level (Rubin, 2018)

\begin{tabular}{ll}
\hline Location of lesions & Symptoms which may present \\
\hline As high as C5 or above & $\begin{array}{l}\text { Paralysis of respiratory muscles } \\
\text { Quadriplegia }\end{array}$ \\
Between C5 and C6 & Weakness of shoulder aberration and elbow flexion \\
& $\begin{array}{l}\text { Loss of biceps tendon reflex and brachioradialis } \\
\text { tendon }\end{array}$ \\
Petween C6 and C7 & $\begin{array}{l}\text { Paralysis of the limbs and hands but the movement } \\
\text { of the shoulders and elbow flexion may still be } \\
\text { present }\end{array}$ \\
Letween C7 and C8 & $\begin{array}{l}\text { Loss of triceps reflex } \\
\text { Paralysis of hands and limbs } \\
\text { Between C8 and T1 }\end{array}$ \\
& $\begin{array}{l}\text { Horner Syndrome } \\
\text { Paralysis of the limbs } \\
\text { Between T1 and medullary cone }\end{array}$ \\
\hline
\end{tabular}

At any segment of spinal cord lesions, tendon reflexes under the segments will change and loss of urinary, bowel movements controls, and sensation.

Diagnosis of intramedullary spinal tuberculosis can be established through a typical clinical presentation accompanied by systemic constitutional symptoms, evidence of a history of exposure to tuberculosis and neuroimaging modalities (Chen et al., 2016). The presence of acid-resistant basil in histopathological samples, confirmation of tubercles through histological examination or the presence of epithelioid cells on the biopsy will establish the diagnosis but biopsies cannot always be done due to invasive intervention (Jaiswal, 2017). The findings of Mycobacterium tuberculosis in suspected specimens were only 5 $-10 \%$ despite having higher sensitivity. Molecular rapid tests can be done on tuberculoma specimens, but the sensitivity is $79.5 \%$ so that in determining extrapulmonary tuberculosis disease and especially in HIV patients, clinical assessment is needed to start empirical therapy until the results of gold standard examination or negative results (TB Care I, 2014). The best modality for the diagnosis of tuberculoma is MRI which can assist clinicians making invasive intervention decisions (Khan et al.,2018; Changal \& Raina, 2014). Tuberculomas are hypo-isointense lesions in T2-weighted (T1W1) image and low-intensity lesions with or without central hyperintensity (due to wide variations in caseating necrosis) in T2-weighted (T2W1) image. Intense ring enhancement appears in post-contrast administration. Differential diagnosis of intramedullary tuberculomas is neurocysticercosis, lymphoma and metastatic tumors (Khan et al., 2018). Thoracal segment of spinal cord is a frequently affected part (Chen et al., 2016; Changal \& Raina, 2014). In this patient, we excluded the possibilities of lymphoma and other metastatic tumors by biomarkers tests and tuberculoma lesions appearance in thoracal segment of spinal cord then we diagnosed as intramedullary spinal tuberculoma in AIDS patient.

Surgery is considered on progressive neurological deficits despite adequate medical therapy and the presence of large lesions that cause significant spinal cord compression (Varghese et al., 2017). Complications of IST are syringomyelia, permanent neurological deficits and spinal defects. Paraplegia as a complication of IST occurs in $23-76 \%$ cases (Chen et al., 2016). Prognosis is affected by earlier confirmation of diagnosis and immediate intervention (Varghese et al., 2017). However, this patient refused surgical intervention although it is indicated.

\section{Conclusion}

From history taking, physical examinations, laboratory tests and neuroimaging, we diagnosed this patient as intramedullary spinal tuberculosis and AIDS.

\section{Acknowledgements}

The authors would like to thank to the deceased patient and his caregivers who allowed this case to be documented. 


\section{References}

Abbasi, F., and Fardkhani, SK., 2014. Paraplegia caused by infectious agents; etiology, diagnosis and management, topics in paraplegia, Available from: https://www.intechopen.com/books/topics-inparaplegia/paraplegia-caused-by-infectious-agents-etiology-diagnosis-and-management accessed on March $4^{\text {th }}, 2019$.

Bosaeed, MA., and Alothman, A., 2017. Pathogenesis of tuberculosis of the nervous system. In M. Turgut et al. (eds.), "Tuberculosis of the Central Nervous System". Springer: Switzerland, 3, p. 23-29.

Changal, K.H. and Raina, A.H., 2014. Central nervous system manifestations of tuberculosis: a review article. Journal of Mycobacterial Diseases, 4(02), p.146-150.

Chen, CH., Chen, YM., Lee. CW., Chang, YJ., Cheng, CY., Hung, JK., 2016. Early diagnosis of spinal tuberculosis. Journal of Formosa Medical Association 115(10), p.825-836.

Center of Diseases Control. 2019. Guidelines for the prevention and treatment of opportunistic infections in HIV-infected adults and adolescents: recommendations from the Centers for Disease Control and Prevention, the National Institutes of Health, and the HIV Medicine Association of the Infectious Diseases Society of America. Available at http://aidsinfo.nih.gov/contentfiles/lvguidelines/adult_oi.pdf accessed on March $4^{\text {th }}, 2019$.

Jaiswal, M., 2017. Spinal Cord. In M. Turgut et al. (eds.), "Tuberculosis of the Central Nervous System". Springer: Switzerland, p. 23-29.

Khan, S., Gupta, S., Jain, S., and Sighania, S., 2018. Concurrent pulmonary, intracranial, intramedullary tuberculoma, and their response to conservative management. International Journal of Recent Surgery and Medicine Science 4, p. 88 - 90.

Nasronudin. 2014. HIV \& AIDS: Pendekatan biologi molekuler, klinis, dan sosial Edisi 2. Airlangga University Press: Surabaya, p. $1-7$.

Rubin, M., 2018. Overview of spinal cord disorders. Available from: https://www.msdmanuals.com/ professional/neurologic-disorders/spinal-cord-disorders/overview-of-spinal-cord-disorders accessed on February $19^{\text {th }}, 2019$.

Schwenkreis, P., Pennekamp, W., and Tegenthoff M., 2006. Differential diagnosis of acute and subacute nontraumatic paraplegia. Deutsches Ärzteblatt 103(44), p. 2948-2954.

TB CARE I. 2014. International standards for tuberculosis care, edition 3. TB CARE I:The Hague. p. 40 - 41.

UNAIDS. 2018. Global HIV \& AIDS statistics - 2018 fact sheet. Available from http://www.unaids.org/en/resources/fact-sheet accessed on February $16^{\text {th }}, 2019$.

Varghese, P., Jalal, M.H.A., Kandathil, J.C., and Mathew, I.L., 2017. Spinal intramedullary tuberculoma. Surgery Journal 3, p. $53-57$. 